\title{
Strategic Suggestions to Make Renewable Energy Economically More Efficient
}

\author{
Jamal Adghough \\ Department of Economics \& Management, Slovak University of Agriculture, Nitra, Slovakia \\ Email address: \\ jamal.adghough@gmx.de \\ To cite this article: \\ Jamal Adghough. Strategic Suggestions to Make Renewable Energy Economically More Efficient. International Journal of Economic \\ Behavior and Organization. Vol. 6, No. 2, 2018, pp. 29-37. doi: 10.11648/j.ijebo.20180602.11
}

Received: April 25, 2018; Accepted: May 22, 2018; Published: June 25, 2018

\begin{abstract}
The term Energiewende (German for energy transition) is a call for the complete abandonment of conventional energies to stop the established climate change. This behavior is interminable and could be achieved only in successive steps. According to this, deployments of renewable energy technologies are considered as a critical approach to sustainable development. Obviously, the renewable energy use can lower a nation's dependency on imported fuels and purchase of energy from foreign markets. It also drives technological innovation and generates employment scheme while enhancing clean development mechanism. This paper presents existing renewable energy use by the example of the country of Morocco and makes use of simple economic approaches to show how technological development leads to improve the economic growth. Subsequently, possibilities are shown to make the use of renewable energies more efficient. The structure of the study is based on suggestions on how to implement innovative processes using renewable energy (solar and wind energy) to use the local resources to develop the economics of the country. The main characteristic of this paper is that it summarizes approaches for renewable energy use tailored for a case of Morocco and that this was not done in literature so far. The recent literature conducted similar case studies for other countries like, e.g., Germany [13], China [27], or for whole economic areas like the European Union, USA [30] or like the MENA-Region [29], and Africa [41], but for Morocco there is a gap in literature. Finally, some key interventions are proposed to achieve economic growth.
\end{abstract}

Keywords: Energy Efficiency, Renewable Energy, Alternative Use of Renewable Energy

\section{Introduction}

Due to its role as a critical key factor in the global economy, the energy sector is undergoing a fundamental transformation. Governments throughout the world have responded to these transformational needs by imposing stringent environmental regulations for emissions control, energy generation, and environmental safety.

In Morocco and all over the world, the energy sector is one of the major drivers of climate change. Additionally, Morocco suffers from a lack of fossil energy sources. This lack leads to a high dependency on energy imports: Morocco imports $96 \%$ of the energy it uses.

Morocco's energy needs also increase while resources are scarce. Primary energy demand has increased on average by up to $5 \%$ in recent years. "For Morocco, energy represents a scarce and expensive resource, which decelerates its dynamic of economic growth" affirmed the Moroccan economist [9].
In 2011 , the country imported $95.6 \%$ of its energy demand. Petroleum imports account for $20 \%$ of total imports and $50 \%$ of the current trade deficit. Further, energy consumption in the Northern African country has risen at an average annual rate of $5.7 \%$ from 2002 to 2011 due to economic growth, population growth and increase in per capita energy consumption [49].

To remedy this dependence, the Moroccan Government launched the Moroccan solar project in 2009 with a first achievement: the NOOR project whose investment cost is estimated at $\$ 9$ billion. This project has a capacity of 2,000 megawatts, this will avoid the issuance of 3.7 million tons of $\mathrm{CO}_{2}$ per year and will provide the equivalent of the electricity for 800,000 people [20].

This paper presents existing renewable energy use in Morocco and makes some critical recommendations to induce the development of renewable and sustainable energy systems further. The structure of the study is concluded based 
on suggestions how the implementation of innovative processes using local natural resources can boost the development in Morocco.

The first part of this paper briefly provides some reasons that make renewable energy (RE) an imperative for Morocco because of its function as a unique source of wide-ranging opportunities. After providing an overview of the currently used energy technologies in Morocco, this paper will present some alternative technologies which could help Morocco to become independent from energy imports and to develop its agricultural and human resources. In light of these challenges, some key policy recommendations are identified. These are considered as essential guidelines not only for the Moroccan government but for all countries with similar geographic properties if they intend to successfully pave the way towards taking on the fight against climate change.

\section{Literature Review}

Technological change has a substantial impact on economic growth. Research in this area, therefore, has a long tradition. For example, Toman and Jemelkova (2003) argue in their work "Energy and Economic Development" that energy development is an integral part of the enhanced economic development and that most of the literature on energy and economic development discusses how development affects energy use rather than vice versa. They also showed the importance of energy development for economic development [26]. However, David Stern pointed out the importance of energy in economic growth. In his work, he mentioned that understanding the role of energy in economic growth requires an understanding of the role of energy in production. In this way, he concluded that all economic processes require energy and that energy is an essential factor of production [44]. According to his research, only some growth models such as that of Solow (1956) and that of Hick's (1932) include resources, energy, and technological improvement. In their models, they attempt to consider research and development activities as an outcome of the decision made by firms and management. The AKmodels represent those models and show the relationship between capital $\left(\mathrm{A}^{*} \mathrm{~K}\right)$ and output $(\mathrm{Y})$. This relationship can be written as $\mathrm{Y}=\mathrm{AK}$, where $\mathrm{A}$ is a constant and $\mathrm{K}$ is a composite of manufactured capital disembodied and technological knowledge. This dependence shows that the growth rate is permanently influenced by the savings rate, which is influenced by $\mathrm{K}$, the composite of manufactured capital and technological knowledge. In other words, when technological knowledge is improved, the factor $\mathrm{K}$ increases and so does the output $\mathrm{Y}$. This provides the evidence that improvement of technological change leads to improvement of economic.

The most research that has been conducted until now focusses on the direct transformation of solar and wind energy into electricity. While, in fact, there are many other technological possibilities worth considering.

As M. A. Abdelkareem showed in his research about [1], renewable energy sources in regions with water deficit like Africa have more relevance if its adoption serves to produce soft water. Further researches done by Dr. P. Plichta show that Silicium can be used as an alternative for organic material for burning processes. [40]. The so-called Silane revolution is about an alternative fuel which is based on Silicium and possesses the property to react with oxygen fully. Regarding the abundant desert in the south of Morocco, which is expanding continuously, the solution presented by Dr. P. Plichta is the best way to kill two birds with one stone.

The main characteristic of this paper is that it summarizes approaches for the use of renewable energy which are tailored for the case of Morocco and which have not been scrutinized in literature so far. In the recent literature, similar case studies for other countries like Germany were conducted and analyzed [13], China [27], USA [30], or for whole economic areas like the European Union, the MENA-Region [29] and Africa [41]. Morocco, however, has not been subject to any of these studies.

Finally, some central interventions will be suggested within reach of the economic growth.

\section{The Importance of Renewable Energy for Morocco}

Morocco suffers from a lack of fossil fuel resources (natural gas and oil). Due to this lack, the country is highly dependent on energy imports to satisfy its needs (e.g., Spain for electricity, among others): $96 \%$ of Moroccan energy is imported. Morocco's energy needs increase, while resources are scarce. Primary energy demand has increased on average by up to $5 \%$ in recent years [8].

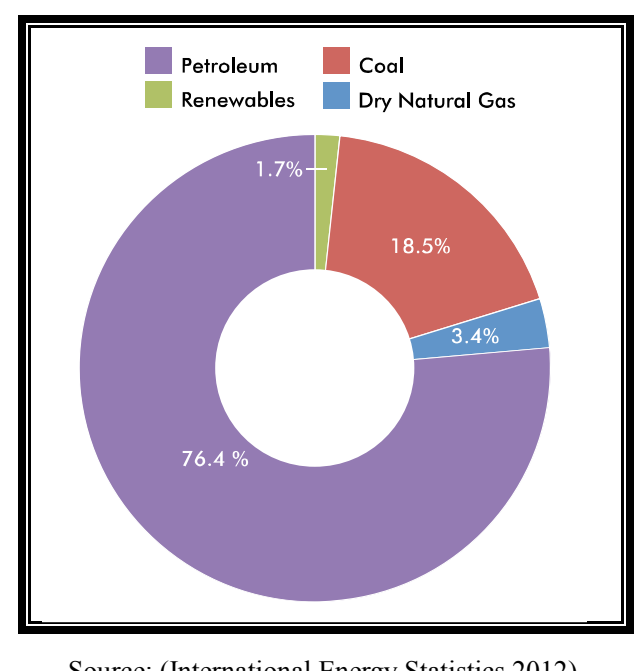

Figure 1. Energy Consumption by Source in Morocco in 2009.

The energy transition can become a key driver for national economic growth and should form the foundation of a national economic strategy to ensure sustainable, long-term prosperity of Morocco. Investment in renewable energy can also be extremely beneficial for Morocco in environmental, 
economic, and social terms. Supporting policies which promote the development of renewable energy can have a variety of wide-ranging benefits. These are:

1. Mitigating climate change according to the agreed COP Policy.

2. Promoting energy security and independence.

3. Benefiting the local economy and creating jobs.

4. Boosting social development and living standards.

5. Reducing pollution benefiting human health.

In general, we can hold on to the assumption that the adaptation of renewable energy in Morocco serves to boost the whole economy of this country. Therefore, a strategy must be embedded into a national economic development plan. In order to achieve this objective, some main interventions are needed. Those are mentioned in the $4^{\text {th }}$ chapter of this paper.

\section{Current Development of Renewables in Morocco}

In the Maghreb region, Morocco leads in the field of renewable energy. As the host of the last COP22 in November 2016, Morocco is seeking to position itself as a developing-world leader in the fight against climate change. Morocco raised its already ambitious energy targets further at the COP21 global climate talks, which concluded in Paris on
December $13^{\text {th }}$. The country now aims to obtain $52 \%$ of its energy supply from renewable energy sources by 2030 . Morocco stands to benefit considerably by easing its reliance on fossil fuels. However, implementing these targets will require a considerable investment from both the government and foreign partners, and implementation is likely to lag behind schedule [45].

In order to promote renewable energy deployment, a strategy that includes three main pillars of action were adopted:

1. The actual regulations and laws according to the electricity regulation are promulgated.

2. New institutions with the capacity to manage renewable energy projects are established.

3. Investment in the infrastructure required for renewable energy facilities.

Since these three pillars have been launched, the development of renewable energy projects in Morocco rose significantly.

In 2009, the Moroccan Government launched the NOOR project as part of the newly established Moroccan solar project. The project's estimated investment costs are about $\$ 9$ billion. It has a capacity of 2,000 megawatts, which will prevent the yearly issuance of 3.7 million tons of $\mathrm{CO}_{2}$ and will provide electricity for 800,000 people [20].

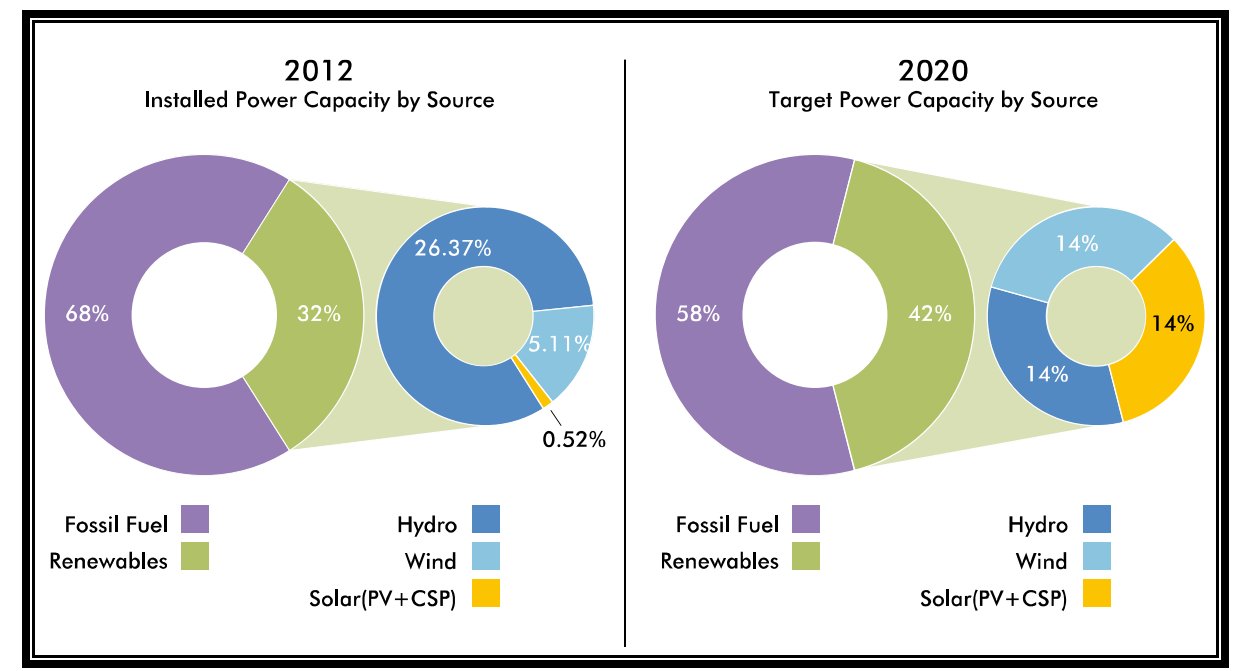

Figure 2. Installed power capacity by source in 2012 and the renewable energy plan until 2020 in Morocco/ Source: (Rcreee, 2013).

As shown in figure 2, the primary renewable energy sources used in Morocco consist of wind, solar and hydro. However, the hydro energy development decreases gradually because of the regional water shortage. Consequently, solar and wind energy could be promoted and developed further.

\section{Innovative Technologies Based on Solar and Wind Power}

In the last century, technology has developed rapidly, the use of automation systems and computers has moved this development into the infinite. Therefore, only a few technical possibilities are mentioned here, which are tailored for the country of Morocco. The suggested solutions are based on the geographical circumstances and the actual socioeconomic situation.

As mentioned before, Morocco controls vast maritime areas with its $3446 \mathrm{~km}$ of marine coastline on which it holds sovereign rights of up to 200 nautical miles setting the exclusive economic zone (EEZ). In addition, the south of the country offers a large amount of sand which can be converted into Silicium. Also, Morocco suffers from a dry climate, especially in the south and east regions. Figure 3 presents the 
possible use of innovative technology which could be implemented into the country's policy to promote renewable

energy further.

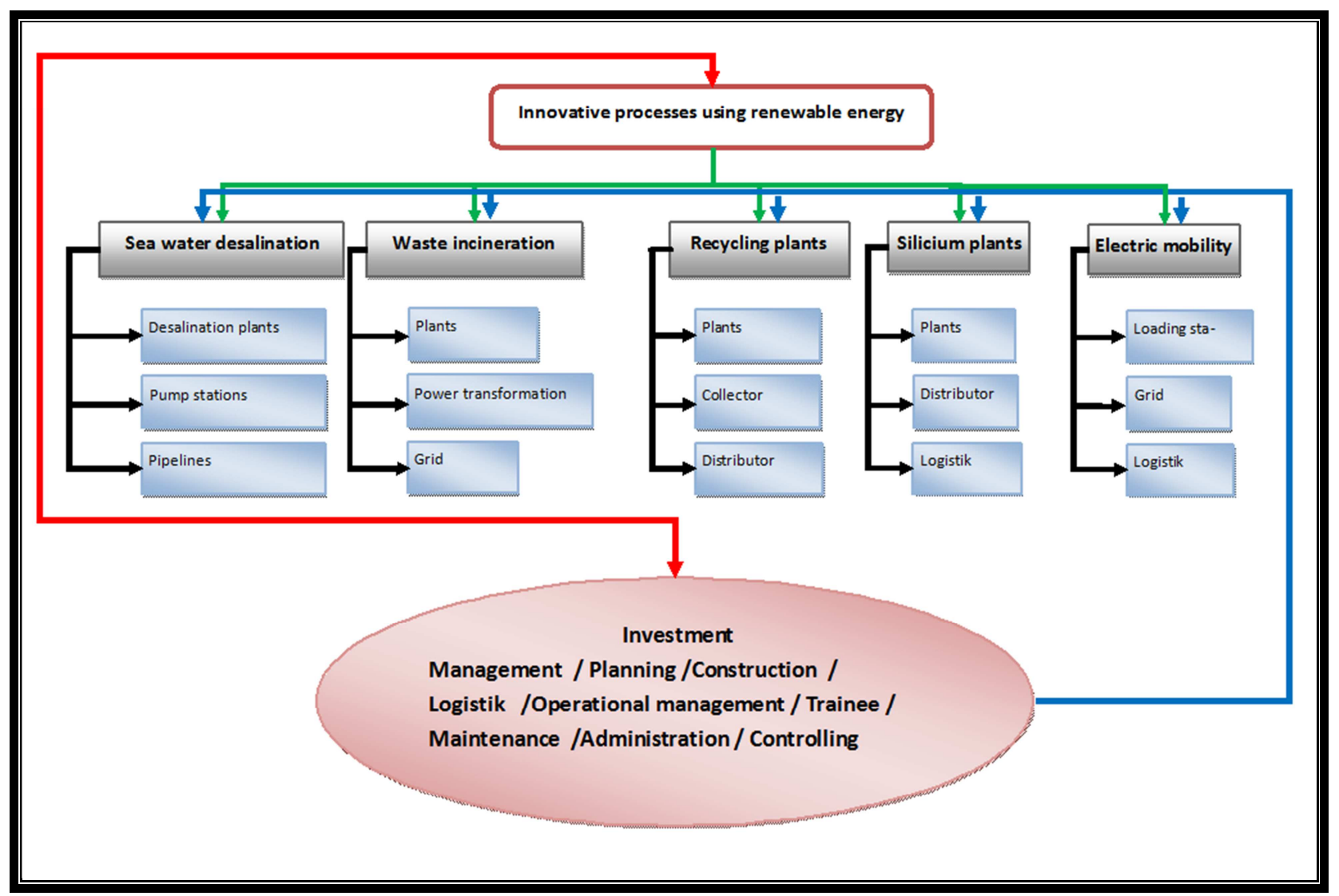

Source: Author's own design.

Figure 3. Suggestion of innovative processes using renewable energy, for the case of Morocco.

\subsection{Water Desalination Units Powered by Renewable Energy}

Water is abundant on earth and covers two thirds of the earth surface. However, only a small portion of this water is suitable for human consumption and use [3].

Currently, $20 \%$ of the world's population is facing scarcity in water resources; $25 \%$ do have access to water, but they lack proper methods to make it potable [48].

This water shortage is expected to affect up to $40 \%$ of world inhabitants by 2030 [47]. Therefore, ensuring sufficient freshwater resources has become a top priority in the strategic plans of most governments as it affects the potential for economic growth and social well-being of billions of people [32].

The use of renewable energy to power desalination plants preserves not only environmental integrity and increases sustainability, but it also has the potential to lower the eventual cost to the end-user - which is crucial for inhabitants of underprivileged societies [37].

Basically, renewable energy can be used in desalination in several forms. The right combination of a renewable energy source with a desalination technology is essential to match both power and water demand economically, efficiently and in an environment-friendly way [42]. Several parameters are governing the selection of appropriate renewable energy system for desalination. Type of available water (brackish or seawater), type and potential of renewable energy sources available in the area, availability of grid electricity, remoteness of the area, plant size, etc. will confine the number of available combinations [22].

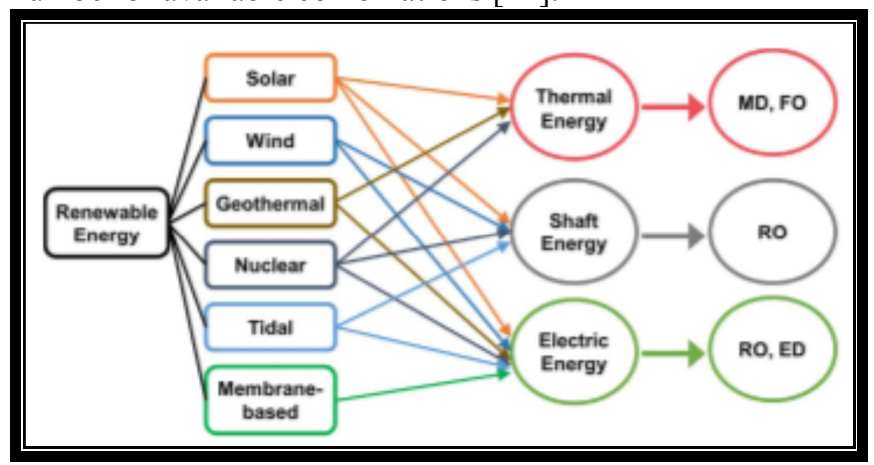

Figure 4. An overview of possible renewable technologies for various membrane-based desalination processes/Source: (Kalogirou, 2005).

Figure 4 shows possibilities for the integration of renewable energy with various desalination techniques. Solar technologies based on solar heat concentration, notably 
concentrating solar power (CSP), produce a large amount of heat which is suitable for MD and FO. PV and wind electricity are often combined with membrane desalination units (RO, ED). As electricity storage is still a challenge, combining power generation and water desalination can also be a cost-effective option for electricity storage when generation exceeds demand. RO and ED can be applied for brackish water as well.

\subsection{Production of Silicium with Use of Renewable Energy}

This chapter is about an innovative opportunity based on the discovery made by Dr. P. Plichta in 2000 about a new synthetic fuel. In his work "Benzin aus Sand" (German for: fuel from sand), which made huge headlines, Dr. P. Plichta presented a new possibility to produce a flammable substance which can be gained from sand and which is comparable with organic fuel based on oil. The chemical reaction of this silicon derivate possesses the property of complete combustion without $\mathrm{CO}_{2}$ in the produced flue gas [40].

The keyword "Silane" is about a combination of silicon and hydrogen. Low Silanes are gaseous. Those with shortchain molecules react explosively when they contact air. When short-chain Silanes are converted to longer-chain molecules through chemical reactions and exclusion of air, their instability decreases, and they can be used as fuel. This chemical reaction requires power which can be generated from solar and wind.

The long-chain Silanes are liquid and can be burned in an internal combustion engine. This results in only water and sand as a spin-off. Because modern combustion engines would wear out with the sand in the fuel over time, the pistons and the combustion chamber would have to be coated with ceramic.

The resulting sand could be collected in a kind of silencer, which has a separator and be recycled later. By this burning process, the performance of the engines will not be reduced.

Considering the fact that the earth's desert-belt offers a huge volume of sand (Silicon-Oxide $\mathrm{SiO}_{2}$ ), the life circle is then completed: The free Sand can be processed to produce Silicon $(\mathrm{Si})$ which is elementary to produce the new synthetic fuel. This is possible with the help of an electric arc furnace. The power required to operate this process can be produceddepending on the location - with the help of solar panels or wind turbines respectively.

The produced $\mathrm{CO}_{2}$ according to the burning process can be converted into Methanol $\left(\mathrm{CH}_{3} \mathrm{OH}\right)$ which, on the other hand, can be used for the chemical industry.

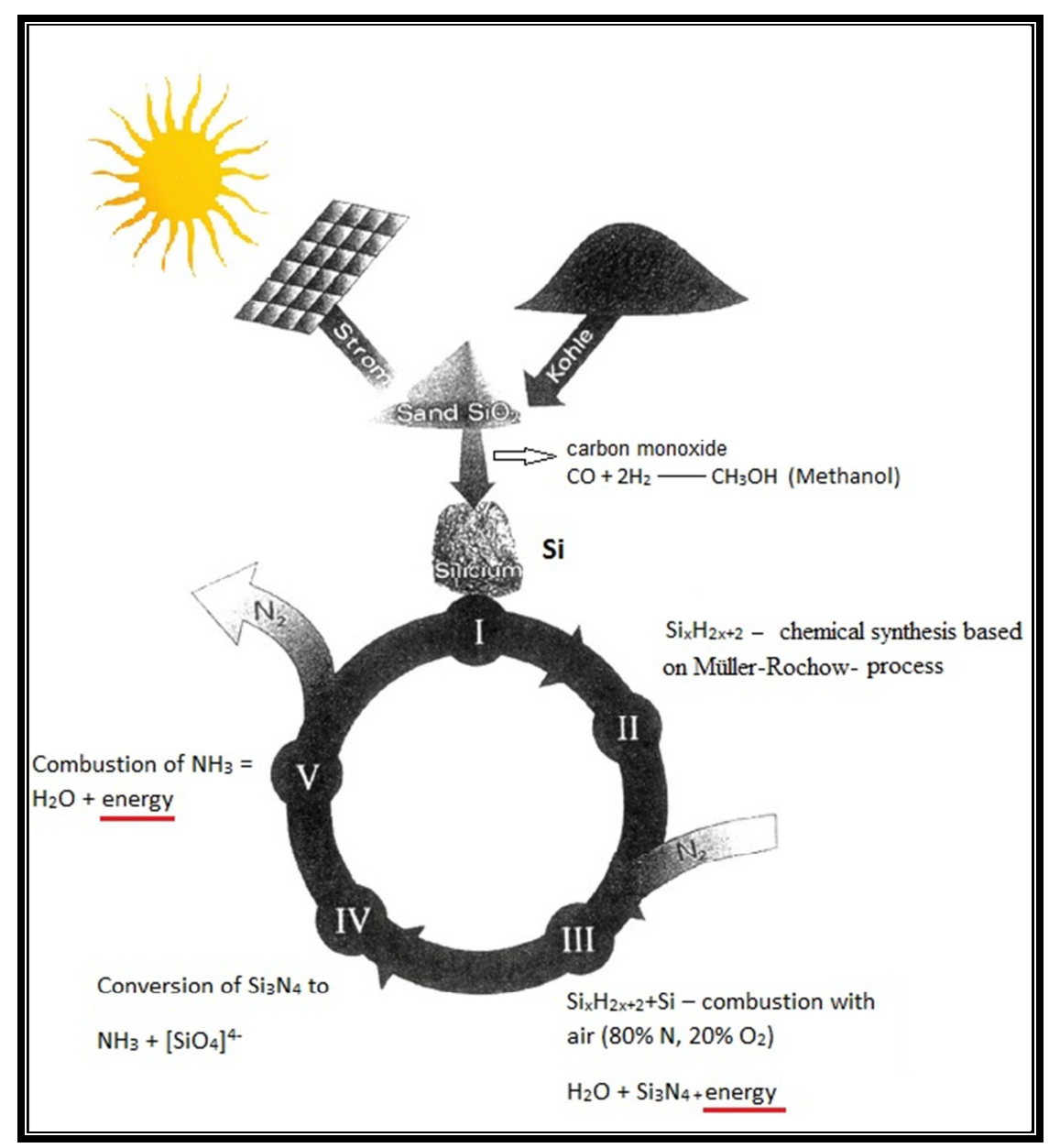

Source: (Herbig, Benzin aus Sand, erweiterte Auflage und zweite Auflage 2006).

Figure 5. Inorganic Silicon Nitride cycle. 
Solar power generates electricity in solar panels. The required electricity can be produced by use of solar panels and can reduce sand and coal in the electric arc furnace. With the help of the Müller-Rochow process, we get silyl halogen (higher silane). This could be burned on site with air which generates a high energy yield to water and silicon nitride. With the help of a basic medium (Alcan), Silicon Nitride $\mathrm{Si}_{3} \mathrm{~N}_{4}$ can be converted into ammonia and silicate. Ammonia is burned with energy yield to Nitrogen and water.

\subsection{Waste Incineration}

The process of waste incineration is, in fact, a relatively old technology. The first plant was built at the beginning of the last century. Nowadays, modern plants can be supported by renewable energy sources which make the entire process more efficient.

In Morocco, there is a lack of these plants. However, there is an excess of waste in the country which could be used as a resource. the waste in this country is all around.

The implementation of these plants in the waste management system will support the welfare and boost the local economies.

\subsection{Electric Mobility}

More than 100 years ago, the first motorized vehicles appeared on the streets. Today we are facing the next revolution of transportation technology, electric mobility (emobility). A sustainable innovation like the electric car can help to decrease the negative externalities of economic growth and reduce the ecological footprint of modern-day life. After a research-intensive period, it is now possible to express a clearer view on the development of electric mobility. According to the research efforts during the last decades, as a result, different electric powertrain types have been developed. There are several powertrain alternatives under development, with different electricity storage solutions and different drivetrain possibilities. We distinguish between six types of Electric Vehicles (EVs): Plug-in hybrid EVs (PHEVs), Range-Extended EVs (REEVs), Battery EVs (BEVs), Fuel Cell EVs (FCEVs), and the (conventional) Hybrid EVs (HEVs) [34].

Also, Europe has gone through the initial adoption phase of electric mobility.

Adopting this challenge should be on the focus of the Moroccan policy, especially during the actual expansion phase of EVs to be aware of the required infrastructure providing this expected revolution.

\section{Economic Aspects of the Case of Morocco}

Morocco belongs to the MENA-Region (the Middle East and North Africa Region) and is considered as one of the countries which are politically most stable. It has a population of 36 Million with an average age of 28 years
[50]. Despite its big capacity of human resources, Morocco's population suffers from unemployment. Morocco's employment rate is too low. In particular, the participation rate of women is as low as $25 \%$ and tends to decrease further. This harms the economy because a significant part of the workforce remains unused [17]. Figure 3 shows the employment rate in Morocco compared with regional and international levels.

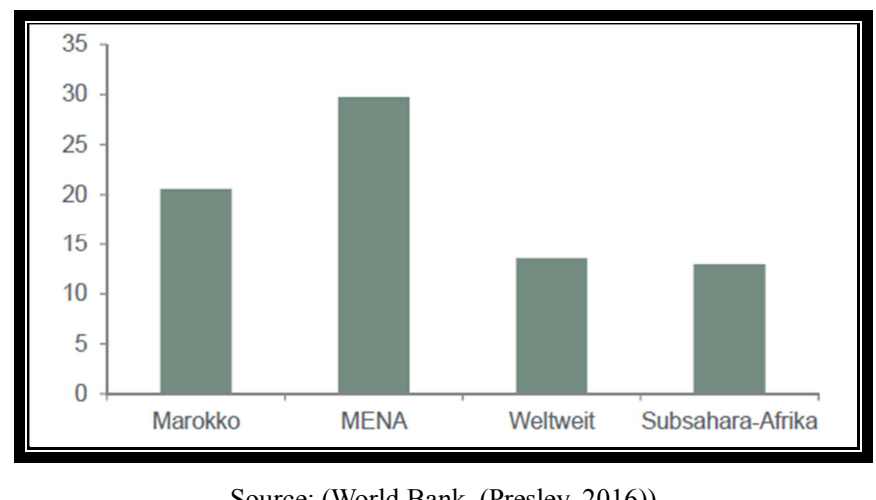

Figure 6. Employment rate in Morocco compared with regional and international levels.

Because of its natural resources, its proximity to Europe, particular attention is paid to Morocco as a renewable energy cooperation partner of Europe. The recent political movement, the so-called "Arab Spring" has proven that Morocco is one of the most stable countries in the region.

\subsection{Recent Developments}

The inconsistency of the weather affects Morocco's economic growth. In 2016, for example, the country has suffered from a severe drought. As a result, the agricultural production, which still represents almost $15 \%$ of Morocco's GDP, decreased by around $10 \%$ and dragged the overall GDP growth down to $1.1 \%$ in 2016. Despite large public investment efforts in recent years, non-agricultural growth remained slow at around 3\%. While the unemployment rate decreased slightly to $9.4 \%$, it masked a protracted decline in the labor force participation rate, which is now well below $50 \%$. The number of young adults aged 15-24 not in education, employment or training reached an estimated 1.7 million in 2016. With an exchange rate pegged to the Euro and U.S. Dollar, inflation has remained below 2\% [51].

Prudent macroeconomic policies have helped to reduce external and fiscal imbalances in recent years. The completion of the subsidy reforms initiated in 2014 coupled with solid fiscal management and financial oversight contributed to further reducing the fiscal deficit to an estimated $3.9 \%$ of GDP in 2016 and to stabilize the public debt at around $66 \%$ of GDP. Improvements in the government investment-saving balance and the fall in international oil prices led to a significant reduction in the external current account in recent years; which was only reversed in 2016 as a result of the effects of accommodative 
monetary policy and a recovery in investment lending to the private sector. With continued sizeable FDI inflows, Morocco's foreign exchange reserves strengthened further to reach 6.4 months of imports of goods and services at end2016 [51].

\subsection{Economic Effects Using Innovative Technologies}

Actually, to monitor the impacts of the energy transition in an economic system, we can use two methods:

1. Using indicators or

2. Using macroeconomic models.

"The first issue is based on a descriptive analysis of historical data and is particularly suitable to analyze the achievement of targets ex-post and in real time. So, we can get an informative overview of the current situation for the achievement of energy policy objectives" [23], so far they are quantifiable.

The second one is based on a full macroeconomic model analysis that can illustrate interactions between the energy system and the macroeconomic model and determine gross effects on the macroeconomic and sectoral levels. In this case, process-oriented analyses are required to be able to measure changes which are happening after specific packages have been implemented.

In the absence of historical data, only the use of macroeconomic models could help to forecast the effects of the presented technologies on the economics of Morocco. The most abundant data are related to the primary sectors. Data which show the trend of the GDP since renewable energy has been implemented in Morocco are not available.

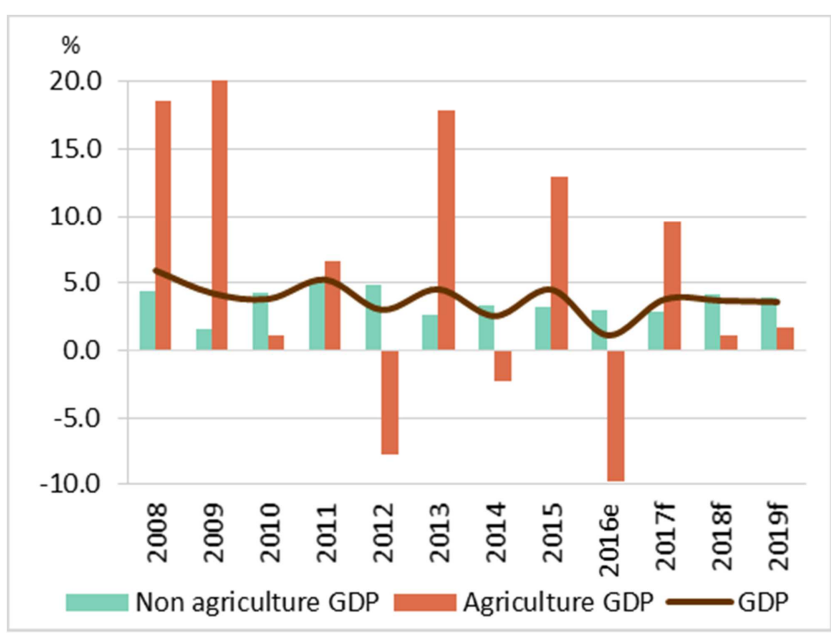

Source: (Morocco's Economic Outlook- April 2017).

Figure 7. Morocco/Volatility of growth rate.

According to figure 7, it becomes evident, that the fluctuations of the agricultural GDP strongly influence Morocco's economy. In this case, we can assume that if we control the swings of the agricultural GDP, we will be able to keep Morocco's economy more stable. To achieve this, we can use some of the technological aspects presented in chapter 5 .

Water desalination plants and pump stations for water distribution as well as a pipe grid can help to produce and to distribute water for irrigation. All those components require electrical power which can be produced using solar and wind. Figure 8 shows the interdependence between economic growth and energy.

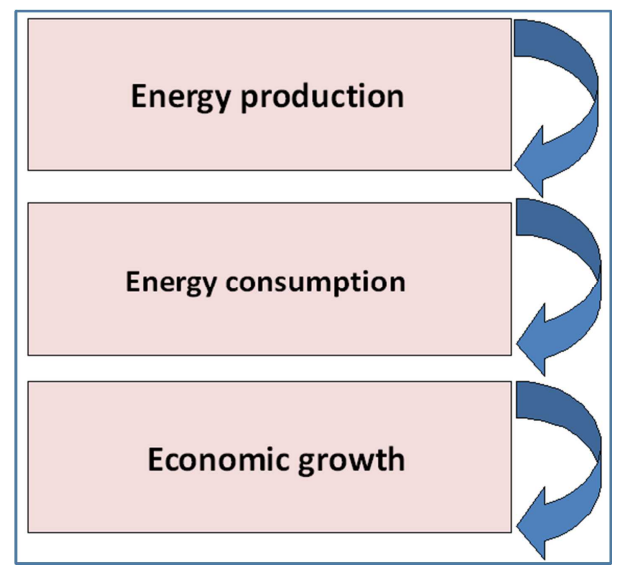

Source: Author's own design.

Figure 8. Causal loop diagram of energy production, consumption, and GDP in Morocco.

\subsection{Theoretical Aspect}

As mentioned in the second chapter of this paper, technological change has a strong impact on economic growth. The work of Fang (2011) shows the influence of renewable energy consumption on the Chinese economy. Thus, we can follow his empirical work to analyze a relationship between inputs and outputs using the general function of Cobb-Douglas. This function has the form of Cobb-Douglas production function [1]:

$$
\mathrm{Q}=\mathrm{AL}{ }^{\alpha} \mathrm{K}^{\beta}
$$

$\mathrm{Q}$ is the monetary value of production, $\mathrm{A}$ is the total factor productivity, $\mathrm{L}$ is the labor input; $\mathrm{K}$ is the capital input. $\alpha$ and $\beta$ are the elasticities of labor and capital respectively.

The labor and capital as variables can be easily quantified as the number of employed people in the country and gross fixed capital formation. Various variables can represent the technological change.

Based on Fang (2011), two variables could represent the possible influence of renewable energy consumption to economic growth:

1. total consumption of renewable energy and

2. share of renewable consumption to the energy mix.

So, the final Cobb-Douglas function can be estimated as follows:

$$
\mathrm{GDP}=\alpha_{0}+\alpha_{1}(\operatorname{trc} \text { or src })+\alpha_{2}(\mathrm{cap})+\alpha_{3}(\mathrm{empl})_{+} \alpha_{4}(\mathrm{R} \& \mathrm{D})_{+} \beta
$$

GDP is the Gross Domestic Product; trc is the total renewable energy consumption; src is the share of renewable energy consumption to total energy consumption; cap is the gross capital formation; empl is the number of employees; $\mathrm{R} \& \mathrm{D}$ is the Research and Development expenditure of each 
country, and $\alpha 0 \ldots \alpha 4$ are the unknown parameters to be estimated while $\beta$ is an error term. Equation (2) shows that the consumption of renewable energy has direct impacts on the GDP.

In this way, the impacts of renewable energy according to the presented technologies seem to be positive for Morocco's economy.

\section{Recommendations}

Despite the effort of the Moroccan government to adopt renewable energy in Morocco's economics, the progress is minimal. This is due to how renewable energy has been implemented: In contrast to leading countries like Germany, Morocco is investing in huge projects to produce electricity while the national grid is meager.

As mentioned in chapter 6.2., investment in water production projects would be more appropriate. Also, decentralism of power production in rural areas would support the rural economics and consistently Morocco's economy. Also, investments in the educative and sensitization of the society would promote the development of renewable energy.

It is about a huge development plan which requires more than the consideration only of the sector of energy separately but also all the other sectors. The project released in Ouarzazate presents the declared attention to participate in the energy transition, but unfortunately, those projects are supported by foreign specialists who are going to take the know-how back once they leave. It is also important to determine which institution is taking the lead in Morocco to ensure the implementation of renewable energy.

\section{Conclusions}

It is widely acknowledged that the Moroccan government had proven considerable commitment to promoting renewable energy. However, many barriers are still present and obstruct further progress. The major obstacles are listed below:

1. The deficit of a master vision supporting $100 \%$ renewable target.

2. The deficit of a strategy adopting $100 \%$ renewable economic development plan.

3. Economic and financial barriers.

4. Market failures and imperfections.

5. Political, institutional governance, and regulatory barriers.

6. Cultural, behavioral, and educational barriers.

7. Technical barriers.

8. Innovation barriers.

The variety of the obstacles listed above cannot be transferred to only one particular institution or entity to implement solutions. Rather, a holistic, shared, and integrated approach should be developed, a kind of master plan needs to be developed, which directs the awareness of society to the vision and steers it in the right direction.

To unlock the full development potential of the sustainable use of renewable energies in Morocco, important challenges still need to be addressed. From a development policy perspective, these hurdles do not relate to equally important questions of system stability or cost efficiency, but rather to RE policy-making. Accordingly, a series of wide-ranging actions is required to mobilize a variety of actors and stakeholders. It is useful to organize the variety of solutions in the following main areas:

1. Definition of tangible goals and developing a vision which provides for changing the actual energy situation. Namely, to adopt a renewable energy policy which supports Morocco to become independent from energy imports and to dispose of the saved expenses on developing Morocco's infrastructure.

2. Set a clear political target which agrees on the developed vision and designs a comprehensive policy framework.

3. Embed a renewable energy strategy into a national economic development plan.

4. Increase collaboration across sectors and governance levels. Especially, a collaboration between the educational and the industrial sectors should be optimized and increased.

\section{References}

[1] Abdelkareem. (2017). Recent progress in the use of renewable energy sources to power water desalination plants".

[2] Aghion, P. H. (2009). The Economics of Growth. MIT Press. Cambridge, MA.

[3] Alex Okibe Edeoja, A. K. (2017). Potentials of Solar Distillation Technologies for Provision of Portable Water for Makurdi Metropolis.

[4] Al-Karaghouli A. A., K. L. (2008-2009). Renewable Energy Opportunities in Water Desalination.

[5] Allan, G. H. (2007). The impact of increased efficiency in the industrial use of energy.

[6] Apostolakis, B. E. (1990). Energy-capital substitutability/complementarity: the dichotomy.

[7] Barnes, D. F. (1996). Rural Energy in (Golden, 2008) Developing Countries: A Challenge for Economic Development.

[8] Benmoussa, M. (04. Mai 2014). Le maroc face au defi energetique. LesEco.ma, S.

$\mathrm{http}: / /$ www.leseco.ma/chronique/141-mohammedbenmoussa/19661.

[9] Benmoussa, M. M. (2014). Publication: 4th Mai 2014 Affichages: 2086. LesEco. ma.

[10] Berlin, B. f. (2012). Die Energiewende in Deutschland. Mit sicherer, bezahlbarer und umweltschonender Energie ins Jahr 2050 .

[11] Berndt, E. R. (1990). Energy use, technical progress and productivity growth: a survey of economic issues. 
[12] Bhattacharya, M. (2016). The effect of renewable energy consumption on economic growth: Evidence from top 38 countries.

[13] Blazejczaka, J. (2012). Economic effects of renewable energy expansion: A model-based analysis for Germany. Elsevier.

[14] Bodell, B. R. (1968). Distillation of saline water using silicone rubber membrane.

[15] Bretschger, L. (2005). Economics of technological change and the natural environment: how effective are innovations as a remedy for resource scarcity?

[16] Brown, S. P. (2002). Energy Prices and Aggregate Economic Activity: An Interpretative Survey. Quarterly Review of Economics and Finance.

[17] Clemens, D. (2017). KfW Research, Schwellenländer Check: Marokko - mit mehr Bildung zum Erfolg.

[18] Cobb-Douglas. (1928). Production function

[19] Commission, E. (1997). Communication from the Commission-Energy for the Future: Renewable Source of Energy-White Paper for Community Strategy Action Plan.

[20] Dakkina, \& Girardet. (2013;2015). 100\% renewable energy: boosting development in morocco.

[21] Darmstadter, J. D. (1979). How Industrial Societies Use Energy. PAPER; 2015.

[22] E. Tzen, D. T. (2008). Autonomous reverse osmosis units driven by RE sources experiences and lessons learned, Desalination 221 (1) 29-36.

[23] Flues-et-al. (2012). Energiepolitische Ziele, Dimensionen und Indikatoren.

[24] G., S. (1902). Reinigung von Zuckersaften durch Electrodialyse und mit Ozon, Germ.

[25] Golden, C. (2008). National Renewable Energy Laboratory.

[26] Greenston, M. (2014). ENERGY, GROWTH AND DEVELOPMENT. IGC Evidence Paper.

[27] Hancheng, D. (2016). The health benefits of developing renewable energy in China towards 2030.

[28] IEAETSAP. (2012). Water Desalination Using Renewable Energy, No.

[29] Kahia, M. (2017). Renewable and non-renewable energy use economic growth nexus: The case of MENA Net Oil Importing Countries.

[30] Kelsey, N. (2018). Who wins in renewable energy? Evidence from Europe and the United States.

[31] Lin, P. K. (2016). Can African countries efficiently build their economies on renewable energy?

[32] M. M. Mekonnen, A. H. (2016). Four billion people facing severe water scarcity, Sci. Adv. 2 (2) 1-6.

[33] Maroc, M. d. (2009). Rapport national relatif aux objectifs du millionaire pour le developpement, 2009 (version anglaise).

[34] McKinsey \& Company. (2017). How automakers can drive electrified vehicle sales and profitability. https://www.mckinsey.de/files/161223_mckinsey_evehicles.pdf: McKinsey.

[35] Meissner, R. (2009). Global freshwater quantity, quality and distribution. Future challenges of providing high-quality water, Vol I Oxford, UK.

[36] Menegaki, A. N. (2011). Growth and renewable energy in Europe: a random effect model with evidence for neutrality hypothesis.

[37] Negewo, B. (2012). Renewable Energy Desalination: An Emerging Solution to Close the Water Gap in the Middle East and North Africa, World Bank Publications.

[38] NinaKelsey. (2017). Renewable and non-renewable energy use - economic growth nexus: The case of MENA Net Oil Importing Countries.

[39] OECD. (2013). Renewable Energies in the Middle East and North Africa. Policies To Support Private Investment. OECD Publishing: Paris.

[40] Plichta, P. (2006). Benzin aus Sand, Second Edition. München, Herbig.

[41] Presley, K. (2016). Can African countries efficiently build their economies on renewable energy?

[42] Ramato Ashu Tufa; et al. (2018). Membrane technology in renewable-energy-driven desalination. Renewable and Sustainable Energy Reviews (S. Vol. 81, issue P1, 1-21). Renewable and Sustainable Energy Reviews.

[43] Richter, T. (. (2012). Entwicklung und Struktur der Wirtschaft. In Naher Osten. Nachbarregion im Wandel; Bundeszentrale für politische Bildung.

[44] Stern, D. I. (2010). The Role of Energy in Economic Growth, CCEP working paper 3.10, Centre for Climate Economics \& Policy, Crawford School of Economics and Government, The Australian National University, Canberra.

[45] The Economist. (2015). Morocco expands its renewable energy goals. Economist, http://country.eiu.com/article.aspx?articleid $=1193782503 \&$ Co untry=Morocco\&topic=Economy_ $1 \#$.

[46] Triebswetter, U. (2011). Kurz zum Klima: Erneuerbare Energien in Nordafrika und im Nahen Osten. ifo Schnelldienst $10 / 2011$.

[47] United Nations World Water Assessment Program, in R. Connor (Ed.). (2015). Water for a Sustainable World. Paris: UNESCO.

[48] W. Xiao-jun, Z. J.-y.-h.-m. (2014). Catastrophe theory to assess water security and adaptation strategy in the context of environmental change.

[49] World Future Council 100\% renewable energy boosting development in Morocco WFC 2015-100. (2015).

[50] WorldBank. (2016). Kingdom of Morocco Financial Inclusion: Technical Note. World Bank, Washington, DC.

[51] WorldBank. (2017). Morocco's Economic Outlook.

[52] Z. (2003). Energy and Economie Development: An Assessment of the State of Knowledge. 